\title{
Estimativa de perda de solo por erosão laminar em Lucena-PB
}

\author{
Estimation of soil loss by laminar erosion in Lucena-PB
}

CARVALHO $^{1}$, H. J. M.; RIBEIRO², C. M.; SANTOS $^{3}$, M. A.; CARVALHO ${ }^{4}$, P. V. R. homerojmc@gmail.com

\section{Resumo}

A erosão laminar provocada pela ação da chuva é um dos problemas ambientais mais frequentes nas cidades, causando diversos danos materiais e humanos anualmente. Esse tipo de erosão é mais intenso em terrenos mais inclinados e com pouca proteção do solo, a exemplo da cidade de Lucena, na Paraíba, onde já se percebem processos erosivos em áreas de intensa atividade agrícola, especialmente nas áreas mais elevadas onde predomina o solo Argissolo Vermelho Amarelo, cuja erodibilidade é relativamente alta. Este trabalho apresenta os resultados de uma avaliação das condições de vulnerabilidade à perda de solo, no município de Lucena, em que foi utilizada a Equação Universal de Perda de Solo (USLE) através de ferramentas de Geoprocessamento a partir de uma carta altimétrica mais precisa, com equidistância de $1 \mathrm{~m}$, o que permitiu a obtenção de um modelo digital do terreno (MDT) com resolução de 10m. Procurou-se, com isso, aperfeiçoar estudos antecedentes para a mesma cidade, revelando-se, aqui, que a resolução do MDT interfere significativamente no resultado final da simulação: MDTs com resolução mais baixa tendem a superdimensionar o fator LS da USLE e, por conseguinte, as estimativas de perdas de solo.

Palavras-chave: Erosão laminar, perda de solo, Equação Universal de Perda de Solo.

\begin{abstract}
The laminar erosion caused by rain is one of the most frequent environmental problems in cities and it has caused several human and material damage every year. Such erosion is more intense in more sloped terrains with less soil protection such as the ones in the city of Lucena in Paraíba, where it is observed erosive processes in areas with intense agricultural activity, mainly in elevated areas where the predominant soil is the Red Yellow Argisol, whose erodibility is relatively high. The current paper presents the results of an evaluation on the conditions of soil erosion vulnerability in the municipality of Lucena, in which it was used Universal Soil Loss Equation (USLE) through Geoprocessing tools from a more precise altimetric map with 1m equidistance, which allowed to design a digital terrain model (DTM) with resolution of $10 \mathrm{~m}$. Thus, it was aimed to enhance the previous studies of the same city, therefore revealing that the DTM resolution significantly interferes in the final result of the simulation: DTW with lower resolutions tend to oversize the LS factor of the USLE and, as it follows, the estimates of soil losses.
\end{abstract}

Keywords: Laminar erosion, soil loss, Universal Equation of Soil Loss.

\section{INTRODUÇÃO}

Identificar os riscos de desastres no ambiente urbano - como os que envolvem a erosão dos solos -, caracterizá-los e mensurá-los não é tarefa fácil, e requer uma base de dados extensa e de boa qualidade sobre as características físicas, sociais e econômicas do espaço geográfico, além de uma equipe técnica multidisciplinar competente, que tanto possa avaliar e

\footnotetext{
${ }^{I}$ Homero Jorge Matos de Carvalho, Grupo de Pesquisa em Qualidade do Ambiente, Instituto Federal da Paraíba, João Pessoa-PB, Brasil.

${ }^{2}$ Carlos Alberto de Mendonça Ribeiro, Universidade Federal da Paraíba, João Pessoa-PB, Brasil.

${ }^{3}$ Marconi Antão dos Santos, Grupo de Pesquisa em Qualidade do Ambiente, Instituto Federal da Paraíba, João Pessoa-PB, Brasil.

${ }^{4}$ Paulo Victor Rodrigues de Carvalho, Comissão Nacional de Energia Nuclear, Instituto de Engenharia Nuclear, Rio de Janeiro-RJ, Brasil.
} 
estabelecer diretrizes de gestão e mitigação dos riscos quanto elaborar estratégias para aumentar a resiliência diante de possíveis ocorrências (desastres).

Para isso, se faz necessária a implantação, em todos os municípios, do Cadastro Técnico Multifinalitário - CTM, que "será o inventário territorial oficial e sistemático do município, embasado no levantamento dos limites de cada parcela, que recebe uma identificação numérica inequívoca" (PHILIPS, 2010). Devem ser englobados, no CTM, cadastros temáticos sobre diversas características do território que possibilitem a identificação dos riscos de desastres.

No caso dos riscos relacionados à erosão laminar causada pela incidência da chuva sobre o solo, serão necessários os cadastros temáticos da classificação dos solos (pedologia), da morfologia do terreno (hipsometria e declividades), do uso e ocupação do solo, das atividades preservacionistas e da pluviometria.

A erosão laminar é um tipo de erosão provocada, principalmente, pela ação de chuvas intensas sobre solos descobertos e frágeis. Ao incidir sobre o solo e escoar, a chuva desloca lentamente parte das camadas superficiais do solo, promovendo diversos danos, como, entre outros, a degradação do solo, a poluição dos mananciais, redução da produtividade de áreas agrícolas e assoreamento de corpos d'água (BRASIL, 2008), entupimento de galeria de drenagem urbana, com consequências graves, sejam, econômicas, sociais ou ambientais.

Sua identificação precoce é importante para as ações de prevenção de desastres. Mesmo que ainda não se identifique a ocorrência de erosões, é possível, através de simulações com o uso de geotecnologias, identificar as áreas mais vulneráveis à sua ocorrência. Neste sentido, este trabalho se propõe a identificar, no município de Lucena, a vulnerabilidade do solo à erosão laminar, ação a partir da qual se espera mapear possíveis áreas de riscos de desastre relacionados a esse fenômeno. Essa vulnerabilidade já foi identificada por Dias \& Silva (2015), que utilizaram o Modelo Digital de Elevação (MDE), proveniente da missão Shuttle Radar Topography Mission (SRTM) desenvolvido pela National Aeronautics and Space Administration (NASA), com resolução espacial de 90m e precisão altimétrica absoluta de $16 \mathrm{~m}$. Neste trabalho, objetivando maior precisão altimétrica, o modelo digital foi desenvolvido a partir de curvas de nível com equidistância de $1 \mathrm{~m}$.

\section{METODOLOGIA}

Todo este trabalho foi realizado através do software Quantum GIS 2.16.2, escolhido não apenas por sua qualidade, mas também por ser gratuito, de modo a incentivar as prefeituras 
que não dispõem de recursos para a aquisição de tecnologias que auxiliem no desenvolvimento de suas práticas de gestão e planejamento a buscar ferramentas que não impliquem custos.

O primeiro passo foi elaborar o mapa do fator R, tomando como referência o trabalho de Amaral et al. (2014). Em seguida, elaborou-se o mapa do fator K (erodibilidade do solo), a partir da vetorização do mapa de solos disponibilizados pela AESA, à qual foram associados os valores de erodibilidade encontrados na literatura para as diferentes unidades pedológicas verificadas no município de Lucena, compilados e utilizados por Dias \& Silva (2015), também para a cidade de Lucena.

Para se obter o fator de relevo (LS), inicialmente foi produzido o mapa hipsométrico, gerado a partir das informações altimétricas de curvas de nível (espaçadas a cada 1 metro) e pontos cotados, presentes nas cartas topográficas, em escala 1:10.000, do ano de 1985, obtidas através do Instituto de Terras do Estado da Paraíba (INTERPA). As informações altimétricas foram interpoladas a fim de gerar o modelo matemático com valores de altitude denominado de TIN (Triangulated Irregular Network), com células de 10 x 10 metros de resolução, portanto, com resolução superior à utilizada por Dias \& Silva (2015) para a mesma cidade, cujas células eram de 90 x 90 metros.

Posteriormente, utilizou-se a ferramenta r.slope, que permite definir a declividade do terreno em porcentagem a partir de arquivos raster. Os parâmentos para definir o fator LS foram calculados a partir da equação proposta por Bertoni \& Lombardi Neto (2008):

$$
\mathrm{LS}=0,00984 \cdot \mathrm{C}^{0,63} \cdot \mathrm{D}^{1,18} \quad \text { Eq. } 05
$$

Onde LS é o fator de relevo, T é a perda de solo em $\mathrm{Kg} / \mathrm{m}^{2}$, $\mathbf{D}$ é o grau de declive do terreno, em \%, e $\mathbf{C}$ é o comprimento de rampa do terreno, em metros, definido pela resolução do arquivo raster (10 metros). Essas equações foram aplicadas aos dados de declividade do terreno, que, por sua vez, foram calculados através de ferramenta "Calculadora Raster" do software Quantum GIS 2.16.2.

Por fim, deu-se o desenvolvimento do mapa de erosibilidade, executando a operação da equação universal, realizada por meio da ferramenta "Calculadora Raster" do Quantum GIS 2.16.2 para a obtenção do mapa de perda de solo do município de Lucena. 


\section{RESULTADOS}

Para o estudo da estimativa de perda de solo por erosão laminar, há que se considerar a relação entre diversos fatores característicos do terreno, do seu uso e ocupação, assim como do clima da localidade onde ele se encontra (Figura 1).

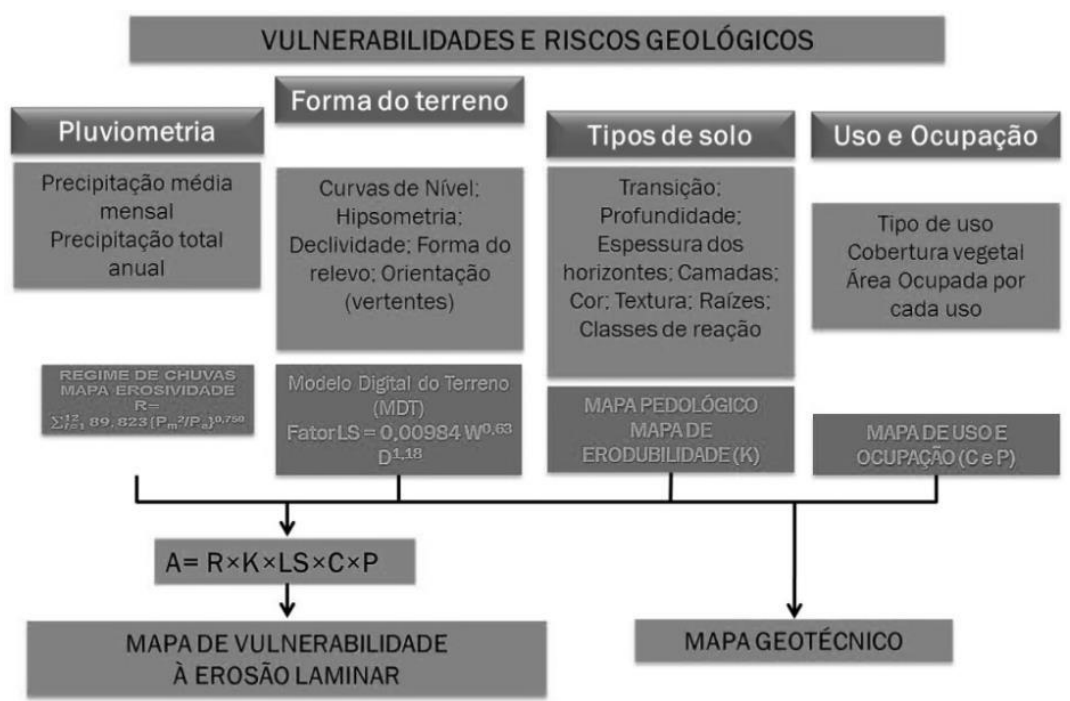

Figura 1: Vulnerabilidade e riscos relacionados à erosão laminar provocada pela chuva. Fonte: Próprios autores.

O ideal é que todos os municípios tenham os dados relacionados a esses fatores registrados e atualizados sistematicamente, num sistema de dados geográficos (SIT), possibilitando a avaliação e a prevenção continuada dos riscos de erosão por especialista, de preferência em escala 1/1.000 ou 1/2.000, que são escalas usuais no planejamento urbano.

Como não há estação meteorológica na cidade de Lucena, utilizaram-se os dados apenas da estação meteorológica mais próxima, que está situada na cidade de João Pessoa (a cerca de $21 \mathrm{~km}$ em relação ao Centro de Lucena). Entendeu-se que assim se alcançaria/obteria maior precisão do que os valores obtidos/alcançados por Dias \& Silva(2015), para a mesma localidade, a partir de dados de diversas estações (mais distantes), através de modelo de interpolação (Krigagem), cuja configuração não foi descrita pelos autores, dando a entender que utilizaram a configuração padrão do software (default), deste modo, com pouca confiabilidade.

Assim, adotou-se um valor de $\mathrm{R}$ único para toda a cidade, $\mathrm{R}=8624,37$ MJ.mm/ha/h/ano, obtido de Amaral et al. (2014), que é considerada alta, segundo Santos (2008). 
O mapa de erodibilidade foi definido a partir dos parâmetros apontados na Tabela 1, compilados e utilizados por Dias e Silva (2015), também para a cidade de Lucena. Através do mapa de erodibilidade (Figura 2), nota-se que a região de planície é formada, predominantemente, por solo dos tipos Neossolo Flúvico e Neossolos Quartzarênicos Marinhos Distróficos, com erodibilidade relativamente alta. Na planície, ao Norte do município ainda se encontra uma porção formada por Solos Indiscriminados de Mangue, que tem a menor erodibilidade entre os tipos de solo encontrados na cidade.

A região mais alta, e com maiores declividades, é formada, predominantemente, por Argissolo Vermelho Amarelo e pequena porção de Espodossolo Hidromórfico, sendo o primeiro o de maior erodibilidade (Tabela 1 e Figura 2).

Tabela 1: Erodibilidade dos solos (fator K) do município de Lucena. Fonte: ${ }^{(1)}$ Távora et al. (1985); ${ }^{(2)}$ Costa e Silva (2012); ${ }^{(3)}$ Silva et al. (2007); ${ }^{(4)}$ Silva (2004); ${ }^{(5)}$ Carvalho Júnior et al. (2009), citados por Dias \& Silva (2015).

\begin{tabular}{lc}
\hline \multicolumn{1}{c}{ Tipos de Solos } & Valores do fator K (t.h/MJ.mm) \\
\hline Neossolos Quartzarênicos Marinhos & $0,020^{(1)}$ \\
Distróficos & $0,014^{(2)}$ \\
Espodossolo Hidromórfico & $0,032^{(3)}$ \\
Argissolo Vermelho Amarelo & $0,042^{(4)}$ \\
Neossolo Flúvico & $0,015^{(5)}$ \\
Solos Indiscriminados de Mangue & \\
\hline
\end{tabular}

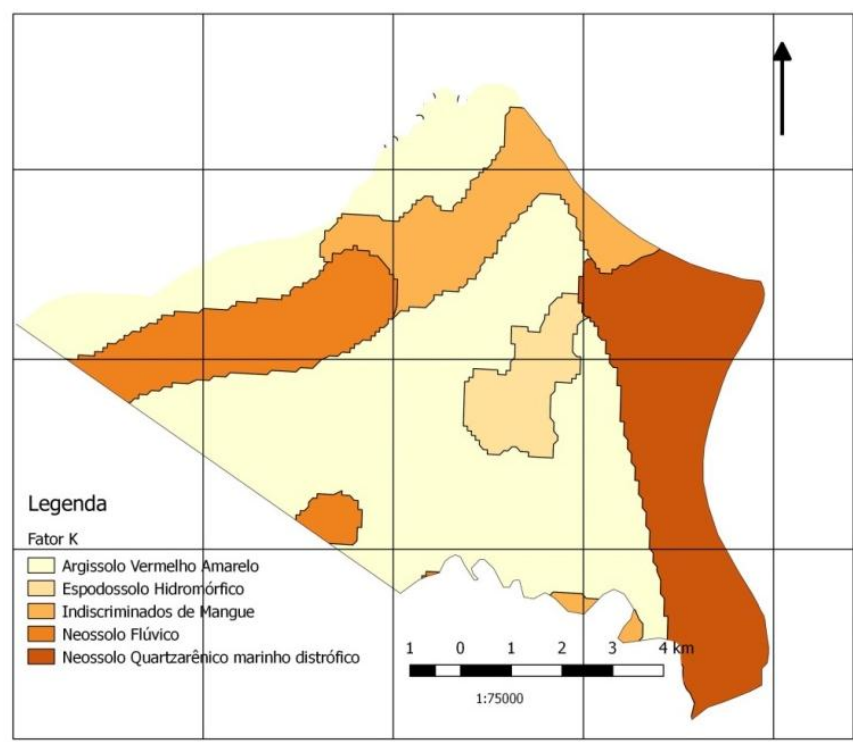

Figura 2: Mapa de erodibilidade (fator K) da cidade de Lucena. Fonte: Adaptado a partir do mapa de Geologia do Estado da Paraíba, publicado pela AESA, disponível em: http://geoserver.aesa.pb.gov.br/geoprocessamento/geoportal/mapas.html

Para se obter o fator LS (Figura 5), primeiro foi necessário elaborar o mapa hipsométrico (Figura 3), derivado de curvas de nível, espaçadas a cada metro, e de pontos 
cotados, conforme descrito na metodologia. Esse mapa define as diferentes alturas do terreno, indicando que Lucena tem uma topografia determinada por uma planície baixa na região litorânea, com altura máxima de $10 \mathrm{~m}$ em relação ao nível do mar, e por um terraço, situado no topo da falésia, com altura que varia de $10 \mathrm{~m}$ a $100 \mathrm{~m}$ de altura, na região Centro-Oeste do município, área ocupada por atividades agrícolas e por algumas porções remanescentes de mata.

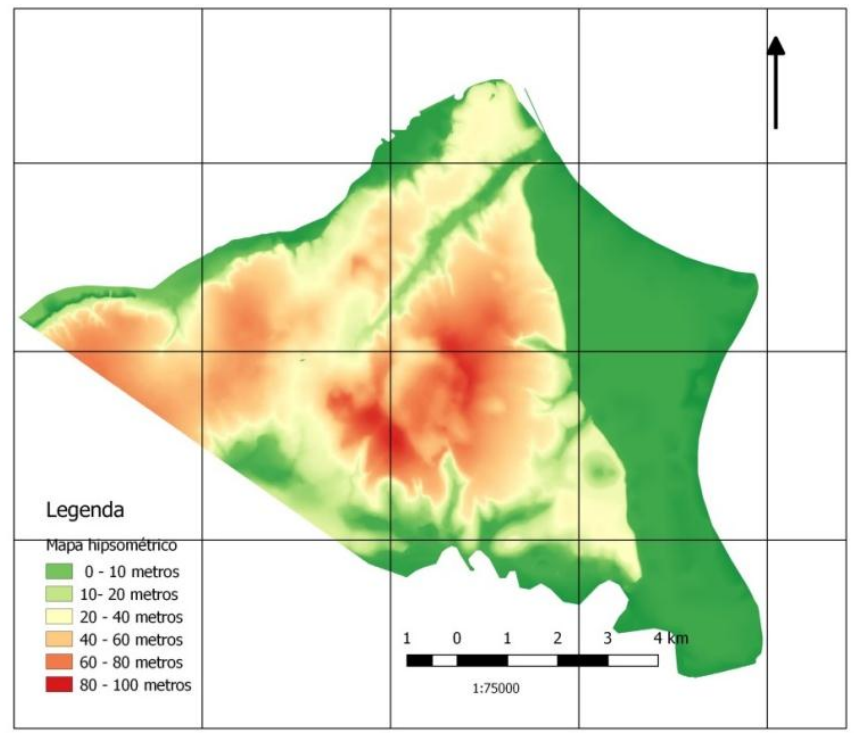

Figura 3: Mapa hipsométrico da cidade de Lucena. Fonte: Adaptado das cartas topográficas, em escala 1:10.000, do ano de 1985, obtidas através do Instituto de Terras do Estado da Paraíba (INTERPA).

A partir do mapa hipsométrico (Figura 3), foi possível obter o mapa clinográfico (de declividade) (Figura 4), que define a inclinação (em \%) das superfícies, identificando-se, por exemplo, as encostas e talude, que são mais sujeitas à ação erosiva da chuva. Note-se, na Figura 4, que as regiões que possuem maior declividade são as de transição da planície litorânea para o tabuleiro (falésia) e as margens dos rios.

A partir dos mapas hipsométrico e de declividade, foi calculado e gerado o mapa do fator topográfico LS (Figura5), que é um valor adimensional representativo da combinação entre o comprimento e o grau de declividade dos planos da superfície (rampas). Os valores mais significativos, acima de 1,35, correspondem às margens dos rios e às regiões de transição entre a planície litorânea e o terraço da falésia, portanto, áreas que requerem maior atenção e proteção, onde a velocidade de escoamento das águas de chuva será maior. 


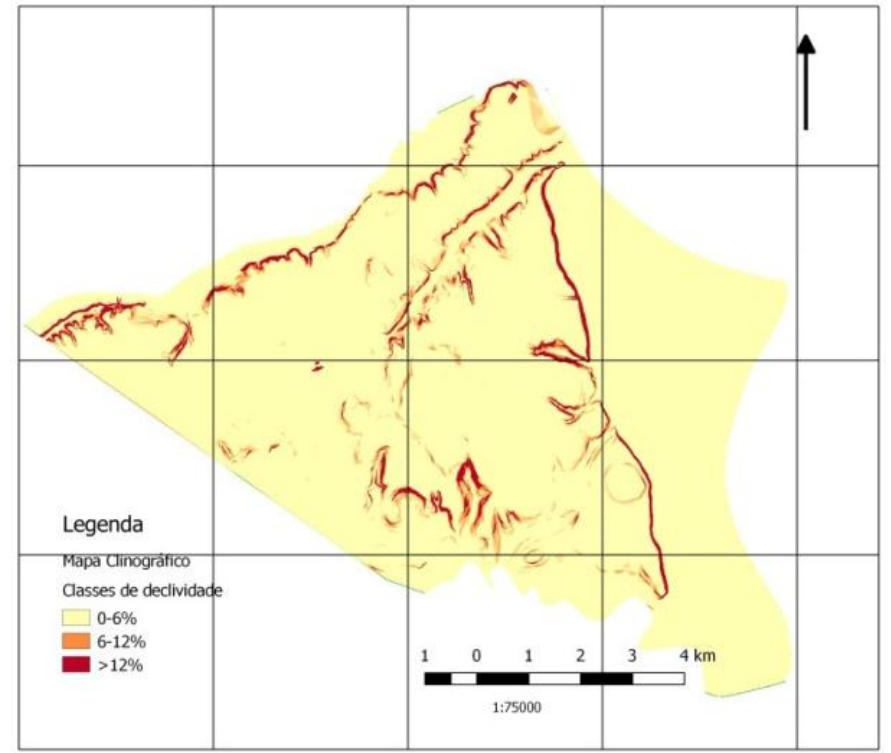

Figura 4: Mapa clinográfico da cidade de Lucena. Fonte: Próprio autor.

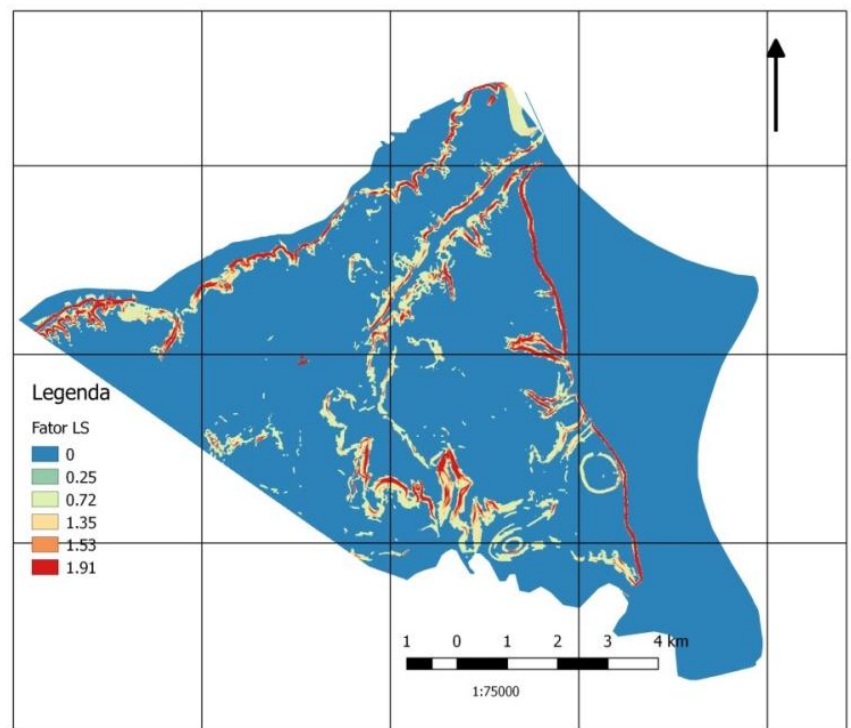

Figura 5: Mapa do fator LS para a cidade de Lucena. Fonte: Próprio autor.

O efeito da erosividade, da erodibilidade do solo e do fator LS dependerá, significativamente, das características de uso e ocupação do solo, que determinam o quanto a superfície está exposta à ação da chuva. Em geral, as áreas mais suscetíveis são as que possuem pouca ou nenhuma cobertura vegetal (solo exposto), representadas, no caso de Lucena, pela ocupação por culturas agrícolas e áreas urbanas não urbanizadas (com ruas sem pavimento ou terrenos sem cobertura vegetal). Note-se no mapa de uso e ocupação do solo que as culturas agrícolas ocupam um maior percentual do território, situando-se nas regiões mais elevadas (Figura 6), a partir da transição entre a planície litorânea e o tabuleiro. 
Constatou-se, como esperado, que as áreas com solo mais exposto e com maior declividade o que se pode observar no mapa de perdas do solo (Figura 7), obtido pela EUSLE, através da álgebra de mapas, são as mais vulneráveis à ação das chuvas e, portanto, à perda de solo por erosão laminar. Essa perda poderá ser maior - atingindo o patamar de 75,1 t/ha/ano nas regiões mais escuras, que correspondem aos limites da falésia, a algumas porções mais acidentadas da região ocupada por culturas agrícolas e às margens dos rios (Figura 8). A vegetação natural que ainda resiste à pressão das lavouras, especialmente de cana-de-açúcar, assumiu papel fundamental na redução da perda de solo em algumas encostas.

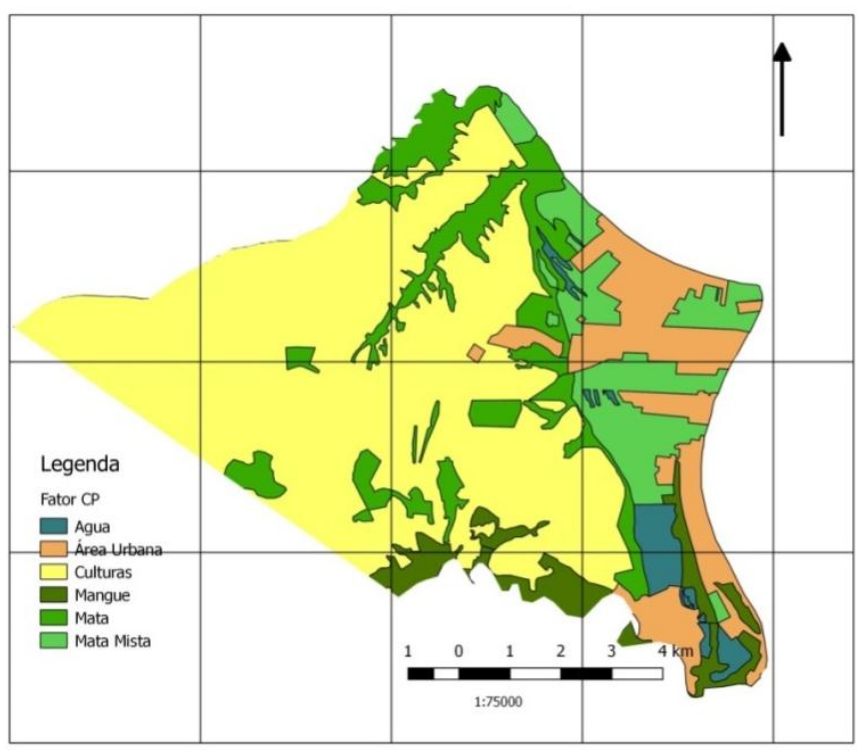

Figura 6: Mapa de uso e ocupação do solo de Lucena. Fonte: Adaptado de imagem do Google Earth (2014).

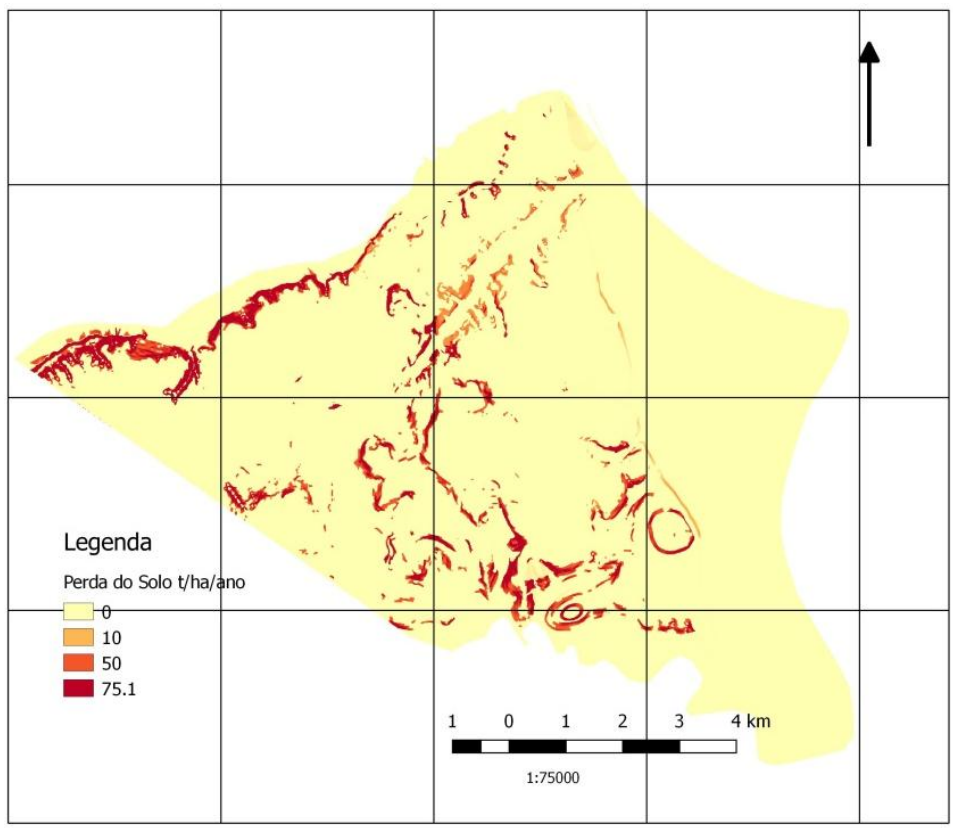

Figura 7: Mapa da estimativa da perda de solo por erosão laminar na cidade de Lucena. Fonte: Próprio autor. 
$\mathrm{Na}$ área urbana, onde há pouca declividade e grande parte superfície pavimentada, não se percebe perdas significativas de solo.

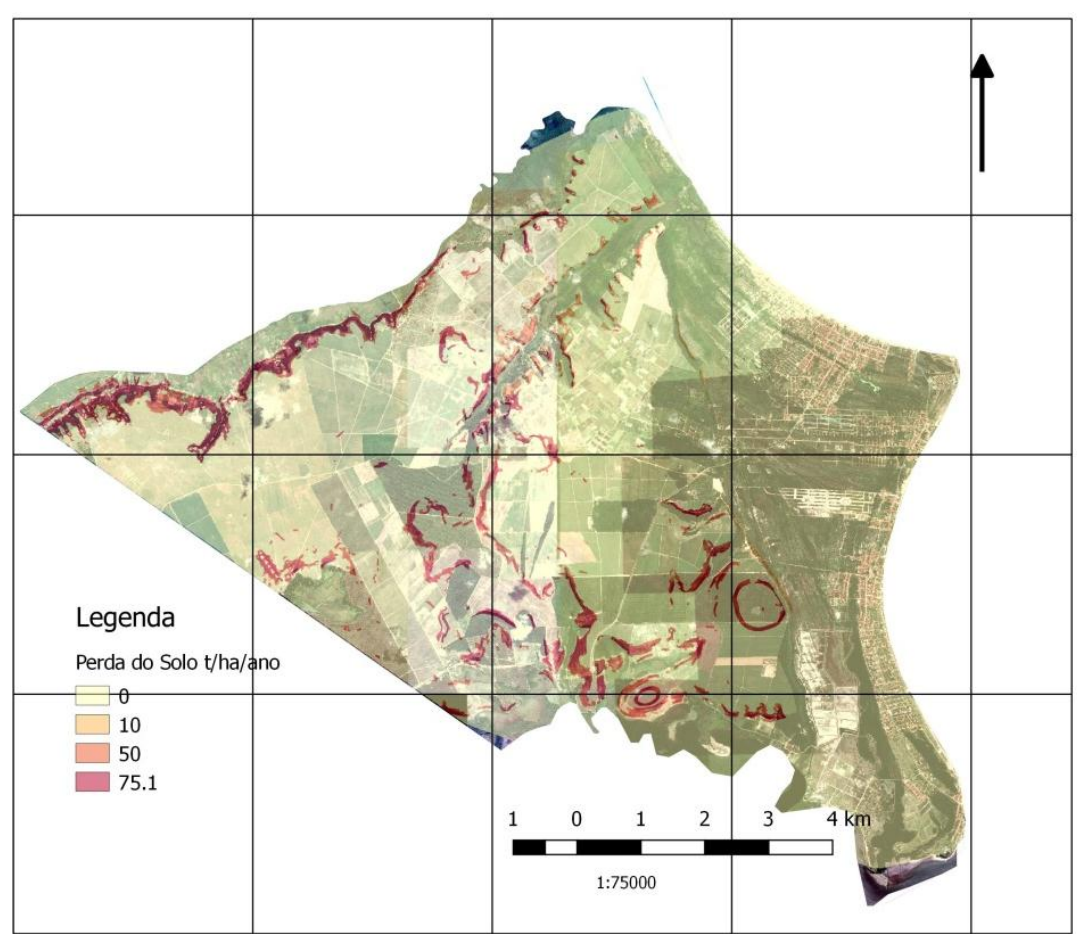

Figura 8: Mapa da estimativa da perda de solo sobreposta à imagem do município de Lucena. Fonte: Adaptação do Mapa da Figura 9 sobreposto à imagem do GoogleEarth (2014).

Essas áreas mais vulneráveis não correspondem, necessariamente, a áreas de risco, pois grande parte dela não está ocupada por pessoas, nem construções. Os principais danos provocados por essas perdas de solo seriam, no caso de Lucena, a redução da fertilidade do solo, a formação de erosões que possam prejudicar a produtividade ou provocar a perda das culturas, e o assoreamento dos rios, tendo em vista que a vegetação ciliar já está bastante comprometida pelas ações antrópicas.

\section{CONCLUSÕES E RECOMENDAÇÕES}

Paranhas et al. (2003) afirmam que a intensidade da erosão de determinada área pode ser influenciada mais pelo declive, características da chuva, cobertura vegetal e manejo, do que pelas propriedades do solo. No caso de Lucena, o declive e as características da chuva são mais determinantes, sendo as perdas maiores nas encostas. Há que se investigar se a cobertura 
vegetal existente nessas encostas está mitigando os efeitos da chuva, o que requer, assim, uma investigação mais aprofundada, em campo.

Comparando os resultados deste trabalho com o de Dias \& Silva (2015), contatou-se que o modelo digital do terreno com resolução inferior - que é o que consta no trabalho desses autores -, ou seja, com células maiores, provoca o superdimensionamento dos valores de LS e, consequentemente, das perdas de solo, mesmo nas áreas onde os valores de erosividade utilizados foram inferiores aos deste trabalho, que coincidem com as regiões mais vulneráreis. Enquanto em Dias \& Silva (2015) a perda de solo passou de $200 \mathrm{t} / \mathrm{ha} / \mathrm{ano}$, neste trabalho a maior perda verificada foi de $75,1 \mathrm{t} / \mathrm{ha} / \mathrm{ano}$.

As divergências deste trabalho em relação ao de Dias \& Silva (2015) revelam a necessidade de confirmar, em campo, os resultados obtidos por meio de simulações computacionais, principalmente quando não se dispõe de dados muito precisos, como os de imagens de baixa resolução e das características pedológicas do local.

Portanto, recomenda-se a realização de novo estudo que verifique, in loco, a existência (ou não) das áreas consideradas vulneráveis e que, partir daí, se investiguem os riscos que porventura já se revelem, oferecendo aos interessados informações que possam eliminá-los ou reduzi-los, criando-se estratégias de mitigação e de prevenção.

\section{REFERÊNCIAS}

AESA. Atlas do Plano Estadual de Recursos Hídricos da Paraíba. Mapa de Geologia da Paraíba. http://geoserver.aesa.pb.gov.br/geoprocessamento/geoportal/mapas.html.

AGOSTINHO, F.D.R. Uso de análise energética e sistema de informações geográficas no estudo de pequenas propriedades agrícolas. Campinas, SP, 2005.

AMARAL, B. S. D.; DANTAS, J. C.; CARVALHO NETO, J.F.; SILVA, R.M. Variabilidade Espacial da Erosividade das Chuvas no Estado da Paraíba. Revista Brasileira de Geografia Física. Recife: UFPE, v. 7, n. 3, p. 691-701, 2014.

BERTONI, J. \& LOMBARDI NETO, F. Conservação do solo. 6 ed. São Paulo: Ícone, 2008. $355 \mathrm{p}$.

BONILLA, C.A.; REYES, J.L.; MAGRI, A. Water erosion prediction using the Revised Universal Soil Loss Equation (RUSLE) in a GIS framework, central Chile. Chilean Journal of Agricultural Research 70 (1), p. 159-169, 2010.

BORGES, K. M. R. Avaliação da susceptibilidade erosiva da Bacia do Rio Carinhanha (MG/BA) por meio da EUPS - Equação Universal de Perda de Solos. 2009. 80p. (Dissertação, Mestrado em Geografia). Departamento de Geografia. Universidade de Brasília. Brasília, 2009. 
BRADY, N. C. Natureza e propriedade dos solos. 7 ed. Rio de Janeiro: F Bastos, 1989, 878p.

BRASIL. Ministério das Cidades/Universidade Federal de Pernambuco - UFPE. Gestão e mapeamento de riscos socioambientais: curso de capacitação/Celso Santos Carvalho, Roberto Quental Coutinho e Thiago Galvão, organizadores - Brasília: Ministério das Cidades; Universidade Federal de Pernambuco - UFPE, 2008. 196 p.

CARVALHO JÚNIOR, W.; CHAGAS, C.S.; FIDALGO, E.C.C.; PEDREIRA, B.C.C.G.; BHERING, S.B.; PEREIRA, N.R. Zoneamento Agroecológico da Bacia Hidrográfica GuapiMacacu. Projeto Entre Serras e Águas - Plano de Manejo da APA da Bacia do Rio Macacu. Instituto Bioatlântica, 2009.

CARVALHO, N. O. Hidrossedimentologia prática. Rio de Janeiro: Ministério de Minas e Energia, CPRM, 1994.

COSTA, S.G.F.; SILVA, R.M. Potencial natural e antrópico de erosão na Bacia Experimental do Riacho Guaraíra. Revista Cadernos do Logepa. João Pessoa: UFPB, v. 7, p. 72-91, 2012.

CPRM - Serviço Geológico do Brasil. Projeto cadastro de fontes de abastecimento por água subterrânea, Estado da Paraíba: Diagnóstico do município de Lucena. Organizado por João de Castro Mascarenhas, Breno Augusto Beltrão, Luiz Carlos de Souza Junior, Franklin de Morais, Vanildo Almeida Mendes, Jorge Luiz Fortunato de Miranda. Recife: CPRM/PRODEEM, 2005.

DIAS, Erika Rodrigues; SILVA, Richarde Marques da. Estimativa do risco à erosão do solo no município de Lucena - Paraíba. Caminhos de Geografia Uberlândia, v. 16, n. 54 Jun/2015 p. 192-204. http://www.seer.ufu.br/index.php/caminhosdegeografia/.

FAO. Metodologia provisional para evaluación de la degradación de los suelos. Roma: FAO/PNUMA: UNEP: UNESCO. 1980. 86 p, 1980.

GOOGLE. Google Earth. Google Inc., 2015. Disponível em: <http://earth.google.com>. Acesso em: 14 de dezembro de 2014.

IBGE. Censo demográfico, 2010.

IDEME. Plano Diretor de Desenvolvimento Municipal, Lucena - PB: Caracterização Geral do Município. V. I, Tomo I, 2001.

PANDEY, A.; MATHUR, A.; MISHRA, S.K.; MAL, B.C. Soil erosion modeling of a Himalayan watershed using RS and GIS. Environmental Earth Sciences. 59 (2), 399-410. 2009.

PARANHAS FILHO, Antonio Conceição; FIORI, Alberto Pio; DISPERATI, Leonardo; LUCCHESI, Cristiane; CIALI, Alessandro; LASTORIA, Giancarlo. Avaliação multitemporal das perdas de solos na bacia do rio Taquarizinho-MS. Boletim Paranaense de Geociências, n. 52, p. 49-59, 2003. Editora UFPR.

PRASANNAKUMAR, V; VIJITH, H.; ABINOD, S.; GEETHA, N.. Estimation of soil erosion risk within a small mountainous sub-watershed in Kerala, India, using Revised Universal Soil 
Loss Equation (RUSLE) and geo-information technology. Geoscience Frontiers 3(2). 209215. 2012.

SANTOS, C.N. El Niño, La Niña e a erosividade das chuvas no Estado do Rio Grande do Sul. 2008. Universidade Federal de Pelotas, Faculdade de Agronomia Eliseu Maciel, Programa de Pós-Graduação em Agronomia.

SILVA, R.M.; SANTOS, C.A.G.; SILVA, J.F.C.B.C. Estimativa das perdas de solo na bacia experimental do rio Guaraíra a partir da EUPS em ambiente SIG. Anais... Porto Alegre: XVII Simpósio Brasileiro de Recursos Hídricos. 2007, ABRH. v. 1. p. 1-13.

SILVA, V. C. Estimativa da erosão atual da bacia do Rio Paracatu (MG/GO/DF). Revista Pesquisa Agropecuária Tropical. Goiânia: UFG, n. 34, v. 3, 147-159, 2004.

STEIN, D. P.; DONZELLI, P. L.; GIMENEZ, F. A.; PONÇANO, E. L.; LOMBARDI NETO, F. Potencial de Erosão Laminar, Natural e Antrópica na Bacia do Peixe-Paranapanema. In: SIMPÓSIO NACIONAL DE CONTROLE DE EROSÃO, 4., 1987, Marília. Anais... Marília: ABGE/DAEE, 1987.

TÁVORA, M.R.P.; SILVA, J.R.C.; MOREIRA, E.G.S. Erodibilidade de dois solos da região de Ibiapaba, Estado do Ceará. Revista Brasileira de Ciência do Solo. Viçosa: SBCS, v. 9, p. 59- 62, 1985.

THOMPSON, D.; FIDALGO, E.C.C. Estimativa da perda de solos por meio da Equação Unicversal de Perdas de Solos (USLE) com uso do Invest para a bacia hidrográfica do Rio Guapi-Macacu - RJ. Anais... Bento Gonçalves: XX Simpósio Brasileiro de Recursos Hídricos, RS, 2013. p. 1-7.

United Nations International Strategy for Disaster Reduction (UNISDR). How to make cities more resilient: a handbook for Local Government Leaders. UNISDR: Geneva, March, 2012.

United Nations International Strategy for Disaster Reduction (UNISDR). Hyogo Framework for Action 2005-2015: Building the Resilience of Nations and 407 Communities to Disasters, Geneva: UNISDR, 2007. United Nations International Strategy for Disaster Reduction (UNISDR). Sendai Framework for Disaster Risk Reduction 2015-2030. Sendai: UNISDR, 2015.

WISCHMEIER, W.H.; SMITH, D.D. Predicting rainfall erosion losses: A guide to conservation planning. Washington, USDA-Agricultural Research, 58p. (Agricultural Handbook, 537), 1965.

ZHANG, Wen-hai; ZHANG, Xing-nan; GAO, Zhi-dong. Factor value determination and applicability evaluation of universal soil loss equation in granite gneiss region. Water Science and Engineering. 2(2): 87-97. 2009.

Recebido em: 13/04/2019

Aceito para publicação em: 25/05/2019 